\title{
First-line afatinib vs gefitinib for patients with EGFR mutation-positive NSCLC (LUX-Lung 7): impact of afatinib dose adjustment and analysis of mode of initial progression for patients who continued treatment beyond progression
}

\author{
Martin Schuler ${ }^{1}$ (I) Eng-Huat Tan ${ }^{2} \cdot$ Kenneth O'Byrne $^{3} \cdot$ Li Zhang $^{4} \cdot$ Michael Boyer $^{5} \cdot$ Tony Mok $^{6} \cdot$ Vera Hirsh $^{7}$. \\ James Chih-Hsin Yang ${ }^{8} \cdot \mathrm{Ki}_{\text {Hyeong }} \mathrm{Le}^{9} \cdot$ Shun Lu $^{10}$. Yuankai Shi ${ }^{11}$. Sang-We Kim ${ }^{12}$. Janessa Laskin ${ }^{13}$. \\ Dong-Wan Kim ${ }^{14} \cdot$ Catherine Dubos Arvis $^{15} \cdot$ Karl Kölbeck $^{16} \cdot$ Dan Massey $^{17}$. Angela Märten ${ }^{18} \cdot$ Luis Paz-Ares $^{19}$. \\ Keunchil Park ${ }^{20}$
}

Received: 21 January 2019 / Accepted: 9 February 2019 / Published online: 19 February 2019

(c) The Author(s) 2019

\begin{abstract}
Purpose In the randomized phase IIb LUX-Lung 7 trial, afatinib significantly improved progression-free survival (PFS) and time-to-treatment failure vs gefitinib in patients with treatment-naïve epidermal growth factor receptor mutation-positive non-small cell lung cancer. We report post hoc analyses of tolerability-guided dose adjustment for afatinib and summarize the clinical characteristics of patients who continued afatinib/gefitinib beyond initial radiological progression in LUX-Lung 7. Methods Patients received afatinib $40 \mathrm{mg} /$ day or gefitinib $250 \mathrm{mg}$ /day until investigator-assessed progression or beyond if beneficial. In case of selected treatment-related adverse events (TRAEs), the afatinib dose could be reduced by 10-mg decrements to minimum $20 \mathrm{mg}$ (only dose interruptions were permitted with gefitinib).

Results All randomized patients were treated (afatinib, $n=160$; gefitinib, $n=159$ ). Sixty-three patients had afatinib dose reduction ( $<40 \mathrm{mg} /$ day; 47 within first 6 months). Dose reduction decreased TRAE incidence/severity (before vs after; all grade/grade 3: $100.0 \% / 63.5 \%$ vs $90.5 \% / 23.8 \%$ ). There was no evidence of significant difference in PFS for patients who received $<40 \mathrm{mg} /$ day vs $\geq 40 \mathrm{mg} /$ day for the first 6 months [median: 12.8 vs 11.0 months; hazard ratio 1.34 (95\% confidence interval 0.90-2.00)]. Twenty-four and 26 patients continued afatinib and gefitinib, respectively, beyond progression in target lesions; median time from nadir of target lesion diameters to initial progression was 6.7 months and 5.6 months. Of these patients, $\sim 70 \%$ had objective response or non-complete response/non-progressive disease in non-target lesions at initial progression.

Conclusions Protocol-defined dose adjustment of afatinib may allow patients to remain on treatment longer, maximizing clinical benefit even in the presence of radiological progression.
\end{abstract}

Keywords Afatinib $\cdot$ EGFR $\cdot$ NSCLC $\cdot$ Dose adjustment $\cdot$ Time-to-treatment failure

ASCO 2016 (poster; dose adjustment); ESMO 2016 (poster; timeto-treatment failure); ELCC 2017 and CSCO 2017 (posters; dose adjustment and time-to-treatment failure).

Electronic supplementary material The online version of this article (https://doi.org/10.1007/s00432-019-02862-x) contains supplementary material, which is available to authorized users.

Martin Schuler

Martin.Schuler@uk-essen.de

Extended author information available on the last page of the article

$\begin{array}{ll}\text { Abbreviations } \\ \text { AE } & \text { Adverse events } \\ \text { CI } & \text { Confidence interval } \\ \text { CR } & \text { Complete response } \\ \text { ECOG PS } & \text { Eastern Cooperative Oncology Group } \\ & \text { performance status } \\ \text { EGFR } & \text { Epidermal growth factor receptor } \\ \text { EQ-5D } & \text { EuroQol 5 dimensions questionnaire } \\ \text { EQ-VAS } & \text { EuroQol Visual Analog Scale } \\ \text { HR } & \text { Hazard ratio } \\ \text { ITT } & \text { Intention to treat }\end{array}$

\section{Abbreviations}

$\mathrm{AE}$

$\mathrm{CR}$

ECOG PS

EGFR

EQ-5D

HR

ITT
Adverse events

Confidence interval

performance status

EuroQol 5 dimensions questionnaire

Hazard ratio

Intention to treat 


$\begin{array}{ll}\text { NCI CTCAE } & \begin{array}{l}\text { National Cancer Institute Common Termi- } \\ \text { nology Criteria for Adverse Events }\end{array} \\ \text { NSCLC } & \text { Non-small cell lung cancer } \\ \text { OS } & \text { Overall survival } \\ \text { PD } & \text { Progressive disease } \\ \text { PFS } & \text { Progression-free survival } \\ \text { PR } & \text { Partial response } \\ \text { PROs } & \text { Patient-reported outcomes } \\ \text { QoL } & \text { Quality of life } \\ \text { RECIST } & \text { Response Evaluation Criteria in Solid } \\ & \text { Tumors } \\ \text { SD } & \text { Stable disease } \\ \text { TL } & \text { Target lesion } \\ \text { TKIs } & \text { Tyrosine kinase inhibitors } \\ \text { TTF } & \text { Time-to-treatment failure }\end{array}$

\section{Introduction}

Established first-line treatment options for patients with non-small cell lung cancer (NSCLC) and activating epidermal growth factor receptor $(E G F R)$ mutations include: the first-generation reversible EGFR-targeting tyrosine kinase inhibitors (TKIs), gefitinib (European Medicines Agency 2018a; US Food and Drug Administration 2015a) and erlotinib (European Medicines Agency 2018b; US Food and Drug Administration 2010); the second-generation irreversible ErbB family blocker afatinib (European Medicines Agency 2018c; US Food and Drug Administration 2013) and the irreversible EGFR TKI dacomitinib (US Food and Drug Administration 2018); and the third-generation EGFR wild-type sparing, irreversible EGFR/T790M inhibitor, osimertinib (European Medicines Agency 2018d; US Food and Drug Administration 2015b). Until recently, there was a lack of prospective head-to-head comparisons of these agents.

The randomized phase IIb LUX-Lung 7 trial is, to the best of our knowledge, the first study to compare the irreversible ErbB family blocker (second-generation EGFR-targeting agent) with a reversible, first-generation EGFR TKI: in this case, afatinib was compared with gefitinib in treatment-naïve patients with advanced NSCLC harboring a common EGFR mutation (exon 19 deletion/L858R) (Park et al. 2016). The primary analysis of LUX-Lung 7 demonstrated that afatinib significantly improved the co-primary end points of progression-free survival [PFS; median 11.0 vs 10.9 months, hazard ratio $(\mathrm{HR})=0.73,95 \%$ confidence interval $(\mathrm{CI})$ 0.57-0.95; $P=0.017]$ and time-to-treatment failure (TTF; defined as the time from randomization to the time of treatment discontinuation for any reason; median 13.7 vs 11.5 months, $\mathrm{HR}=0.73,95 \%$ CI $0.58-0.92 ; P=0.007$ ) vs gefitinib (data cutoff: August 21, 2015) (Park et al. 2016). Analysis of overall survival (OS) demonstrated no significant difference in OS between the treatment groups [median 27.9 vs
24.5 months, $\mathrm{HR}=0.86,95 \%$ CI $0.66-1.12 ; P=0.258$ on April 08, 2016 (Paz-Ares et al. 2017) and HR $=0.85,95 \%$ CI 0.66-1.09; $P=0.195$ on December 05, 2016] (Corral et al. 2017).

The adverse event (AE) profiles for both afatinib and gefitinib in LUX-Lung 7 were consistent with previous experience, with no unexpected safety findings. As expected, diarrhea (afatinib vs gefitinib, all grades: $90.0 \%$ vs $61.0 \%$; grade $\geq 3: 12.5 \%$ vs $1.3 \%$ ) and rash/acne (all grades: $88.8 \%$ vs $81.1 \%$; grade $\geq 3: 9.4 \%$ vs $3.1 \%$ ) were more frequent with afatinib than gefitinib (Park et al. 2016), which is also consistent with observations with another irreversible second-generation EGFR TKI, dacomitinib (Wu et al. 2017). Increased alanine transaminase/aspartate transaminase (all grades: $24.5 \%$ vs $10.0 \%$; grade $\geq 3: 8.8 \%$ vs $0 \%$ ) was more frequent with gefitinib than afatinib (Park et al. 2016).

While the primary results of LUX-Lung 7 favored afatinib over gefitinib in a clinical trial setting, it is essential to consider factors that are likely to contribute toward treatment decisions in 'real-world' clinical practice. Regarding afatinib, a pertinent question is how should AEs, in particular diarrhea, be managed so that patients can remain on treatment for as long as they derive clinical benefit? Furthermore, is AE management with afatinib sufficiently effective in facilitating the 'real-world' clinical practice of continuing EGFR TKIs beyond radiological progression, in the absence of clinical deterioration? This is an important option for physicians and is recognized in current treatment guidelines (Novello et al. 2016), as it appears to reduce the risk of 'disease flare' (sudden increases in tumor growth and disease-related symptoms) in EGFR mutation-positive NSCLC patients with slow progressive disease (PD) (Chaft et al. 2011; Riely et al. 2007; Yap et al. 2017). In LUX-Lung 7, $35.0 \%$ of afatinib-treated and $29.6 \%$ of gefitinib-treated patients continued the assigned study treatment beyond radiological progression. For these patients, median duration of treatment beyond initial progression was 2.7 months (95\% CI 1.9-4.3) and 2.0 months (95\% CI 1.5-3.0), respectively (Park et al. 2016).

Previous studies have demonstrated that a well-established tolerability-guided afatinib dose adjustment protocol, which is facilitated by the availability of several dose strengths (European Medicines Agency 2018c; US Food and Drug Administration 2013), effectively mitigates afatinibrelated AEs without impacting efficacy outcomes (Yang et al. 2016). Therefore, treatment discontinuation due to afatinib-related AEs is rare in clinical trials (6-8\%) (Park et al. 2016; Sequist et al. 2013; Wu et al. 2014). Indeed, the effectiveness of tolerability-guided dose adjustment for AE management may also be reflected in the improvements in TTF observed with afatinib vs gefitinib in LUX-Lung 7 (Park et al. 2016). 
In this sub-analysis of LUX-Lung 7, we further assessed the impact of tolerability-guided dose adjustment of afatinib with respect to AE management, patient-reported outcomes (PROs) and efficacy of treatment. We also evaluated the clinical characteristics of patients who continued afatinib or gefitinib treatment beyond initial radiological progression, to assess the potential for maximizing time on treatment for as long as patients derive clinical benefit.

\section{Patients and methods}

\section{Study design and patients}

Full details of the study design, treatments and assessments used in the LUX-Lung 7 trial have been published (Park et al. 2016). Briefly, LUX-Lung 7 (NCT01466660) was an international, multicenter, randomized, open-label phase IIb trial, conducted in 64 sites across 13 countries. Eligible patients were aged 18 years or older with: treatment-naïve pathologically confirmed stage IIIB/IV adenocarcinoma of the lung, a documented common activating EGFR mutation (exon 19 deletion/L858R), an Eastern Cooperative Oncology Group performance status of 0 or 1, at least one measurable lesion [Response Evaluation Criteria in Solid Tumors version 1.1 (RECIST v1.1)] and adequate organ function. The co-primary end points were PFS by independent central review, TTF and OS. Secondary end points included the proportion of patients with an objective response, tumor shrinkage and longitudinal change from baseline in health-related quality of life (QoL). The incidence and intensity of AEs, graded according to US National Cancer Institute Common Terminology Criteria for Adverse Events version 3.0 (NCI CTCAE v3.0), were also assessed.

LUX-Lung 7 was conducted in accordance with the provisions of the Declaration of Helsinki and Good Clinical Practice guidelines as defined by the International Conference on Harmonization. The study protocol was approved by an institutional review board or ethics committee at each participating center, and all patients provided written informed consent for participation in the trial.

\section{Treatment}

Patients were randomized 1:1 to oral afatinib $40 \mathrm{mg} /$ day or gefitinib $250 \mathrm{mg} /$ day, stratified by $E G F R$ mutation type (exon 19 deletion/L858R) and baseline brain metastases (present/absent). Afatinib dose escalation to $50 \mathrm{mg} /$ day was permitted after 4 weeks of treatment in the absence of grade $>1$ treatment-related AEs. In the event of the following treatment-related AEs, afatinib administration was paused for no more than 14 days until recovery to grade 1 or baseline, after which the afatinib dose was reduced by 10-mg decrements to a minimum dose of $20 \mathrm{mg}$ : any grade $\geq 3$ treatment-related $\mathrm{AE}$, prolonged grade 2 diarrhea, grade 2 nausea or vomiting for $\geq 7$ days despite supportive care or grade $\geq 2$ worsening renal function (European Medicines Agency 2018c; US Food and Drug Administration 2013). Modifications in administration of gefitinib were permitted according to the summary of product characteristics, prescribing information or institutional guidelines. Gefitinib is only approved for administration in one dose formulation (European Medicines Agency 2018a; US Food and Drug Administration 2015a) and so no dose reduction schemes were implemented, but treatment interruptions were permitted. For each AE, the action taken with study treatment was recorded; however, this action taken only captured reductions or discontinuations and not treatment interruptions. In both treatment groups, the assigned study treatment could be continued beyond radiological progression (RECIST v1.1; by investigator assessment) in the case of continued clinical benefit as judged by the investigator. Following discontinuation of the assigned study treatment, crossover to the alternate study treatment was not permitted.

\section{Assessments and statistical analyses}

All randomized patients [the intention-to-treat (ITT) population] from LUX-Lung 7 were included in the analyses. Three analysis time points were planned for LUX-Lung 7. The primary PFS/TTF analysis, planned after 250 PFS events (data cutoff: August 21, 2015), and the primary OS analysis, planned after approximately 213 OS events and a follow-up period of at least 32 months for patients still alive (data cutoff: April 08, 2016), have been published (Park et al. 2016; Paz-Ares et al. 2017). The final analysis will be undertaken at study completion (when all patients have completed treatment, or 5 years after the last patient was entered, whichever occurs first). Here, we present post hoc analyses using data from the primary PFS/TTF time point.

Analysis of the impact of afatinib dose adjustment at any time during treatment included assessment of: time to first dose reduction; exposure to afatinib 40, 30 and $20 \mathrm{mg}$; duration of treatment for patients whose dose was reduced to $<40 \mathrm{mg} /$ day vs those whose dose was not reduced; and frequency and severity of the most common AEs pre- and post-dose reduction from $40 \mathrm{mg}$ (according to the NCI CTCAE v3.0) (National Cancer Institute 2006). For patients whose dose was reduced to $<40 \mathrm{mg}$ within, or remained on $\geq 40 \mathrm{mg}$ /day for, the first 6 months of treatment (the time period when most dose reductions occur), post hoc analysis of baseline characteristics, PFS and PRO QoL outcomes [measured with the EuroQol 5 dimensions questionnaire (EQ-5D) and EuroQol Visual Analog Scale (EQ-VAS) scores] (Park et al. 2016) was conducted. PRO measures were performed until treatment discontinuation. 
For patients who continued treatment beyond initial radiological progression (by investigator assessment), the baseline characteristics were summarized and compared with those of the ITT population; response to treatment in target and non-target lesions at the time of initial progression was also summarized. For those patients with initial PD in the target lesions, further summaries included: maximum percentage decrease in the sum of target lesion diameters before initial progression, best target lesion response, maximum percentage increase in the sum of target lesion diameters from nadir to initial PD, time to initial progression from the time point of the nadir and response of non-target lesions at the time of initial PD. The nadir of target lesion diameters was defined as the smallest sum on study of target lesion diameters (Eisenhauer et al. 2009).

Kaplan-Meier estimates and 95\% CIs were calculated at planned imaging time points and used to estimate the median and quartile values (and 95\% CIs) for PFS. A Cox proportional-hazards model was used to derive HRs and $95 \%$ CIs; groups were compared using a log-rank test. All other analyses were descriptive. Statistical analyses were performed with Statistical Analysis System (version 9.4).

\section{Results}

\section{Patients and afatinib treatment exposure}

In the LUX-Lung 7 trial, a total of 319 patients were randomized to afatinib $(n=160)$ or gefitinib $(n=159)$ and all patients were treated. Baseline characteristics for the overall population have been published and were similar between treatment groups (Park et al. 2016).

At the time of the analysis, 67 of $160(41.9 \%)$ patients had at least one dose reduction of afatinib. Nine (5.6\%) patients had afatinib dose escalations to $50 \mathrm{mg} /$ day, but five $(3.1 \%)$ of these patients experienced subsequent dose reduction to $40 \mathrm{mg} / \mathrm{day}$, one of whom had a further reduction to $30 \mathrm{mg} /$ day. In total, 63 (39.4\%) patients had dose reductions to $30 \mathrm{mg}, 21$ (13.1\%) of whom had further reductions to $20 \mathrm{mg}$. Twelve (19.0\%) patients who had a dose reduction to $<40 \mathrm{mg} /$ day and eight $(8.2 \%)$ patients who received $\geq 40 \mathrm{mg} /$ day throughout remained on treatment at the time of analysis. Median exposure to afatinib $40 \mathrm{mg}$ was 7.4 months, to $30 \mathrm{mg}$ was 7.6 months and to $20 \mathrm{mg}$ was 7.6 months. Median time to first dose reduction was 1.9 months (range $0.4-28.6$ ). The median duration of treatment for patients who received $<40 \mathrm{mg} /$ day at any time was 16.3 months (range 1.1-39.4) and $\geq 40 \mathrm{mg} /$ day throughout was 12.8 months (range $<0.1-40.1$ ).

Of the 67 afatinib-treated patients who had dose reductions, $47(70.1 \%)$ patients had a dose reduction to $<40 \mathrm{mg}$ within the first 6 months of treatment. Baseline
Table 1 Baseline demographics and disease characteristics of patients with/without afatinib dose reductions

\begin{tabular}{|c|c|c|}
\hline Characteristic, $n(\%)$ & $\begin{array}{l}<40 \mathrm{mg} \text { for the } \\
\text { first } 6 \text { months } \\
(n=47)\end{array}$ & $\begin{array}{l}\geq 40 \mathrm{mg} \text { in the first } \\
6 \text { months } \\
(n=113)\end{array}$ \\
\hline \multicolumn{3}{|l|}{ Gender } \\
\hline Male & $11(23.4)$ & $58(51.3)$ \\
\hline Female & $36(76.6)$ & $55(48.7)$ \\
\hline Median age, years (range) & $65(37-86)$ & $62(30-83)$ \\
\hline \multicolumn{3}{|l|}{ Race } \\
\hline Asian & $17(36.2)$ & $77(68.1)$ \\
\hline Black/African American & $0(0.0)$ & $1(0.9)$ \\
\hline White & $21(44.7)$ & 27 (23.9) \\
\hline Missing $^{\mathrm{a}}$ & $9(19.1)$ & $8(7.1)$ \\
\hline \multicolumn{3}{|l|}{ Smoking status } \\
\hline Never smoked & $37(78.7)$ & $69(61.1)$ \\
\hline Ex-smoker & $9(19.1)$ & $39(34.5)$ \\
\hline Current smoker & $1(2.1)$ & $5(4.4)$ \\
\hline \multicolumn{3}{|l|}{ Baseline ECOG PS } \\
\hline 0 & $14(29.8)$ & $37(32.7)$ \\
\hline 1 & $33(70.2)$ & $76(67.3)$ \\
\hline \multicolumn{3}{|l|}{ Histologic classification } \\
\hline Adenocarcinoma & $47(100.0)$ & $112(99.1)$ \\
\hline Mixed & $0(0.0)$ & $1(0.9)$ \\
\hline \multicolumn{3}{|l|}{ Clinical stage at screening } \\
\hline IIIB & $0(0.0)$ & $8(7.1)$ \\
\hline IV & $47(100.0)$ & $105(92.9)$ \\
\hline \multicolumn{3}{|l|}{ Metastases at screening } \\
\hline Adrenal glands & $5(10.6)$ & $7(6.2)$ \\
\hline Bone & $25(53.2)$ & $55(48.7)$ \\
\hline Brain & $6(12.8)$ & $20(17.7)$ \\
\hline Liver & 7 (14.9) & $9(8.0)$ \\
\hline Lung ipsilateral & $26(55.3)$ & $60(53.1)$ \\
\hline Lung contralateral & $17(36.2)$ & $48(42.5)$ \\
\hline Other & $21(44.7)$ & 79 (69.9) \\
\hline
\end{tabular}

ECOG PS Eastern Cooperative Oncology Group performance status ${ }^{\text {a }}$ Patients recruited in French sites did not have their race recorded

characteristics were generally similar between patients who had dose reduction to $<40 \mathrm{mg} /$ day within, or remained on $\geq 40 \mathrm{mg}$ /day for, the first 6 months of treatment (Table 1). Of the 47 patients who had a dose reduction to $<40 \mathrm{mg}$ /day during this time, $36(76.6 \%)$ were female and $30(63.8 \%)$ were non-Asian. In the ITT population, 91 (56.9\%) and 66 (41.3\%) afatinib-treated patients were female and non-Asian, respectively (Park et al. 2016).

\section{Impact of afatinib dose adjustment on treatment-related AEs, PFS and PROs}

As noted previously, if an AE led to discontinuation of study treatment, this was captured for both the afatinib and 
gefinitib treatment groups. If an $\mathrm{AE}$ led to dose reduction, this was also captured; however, this only applied to the afatinib treatment group as a dose-reduction scheme was only implemented for afatinib. Gefitinib label prescription only permitted treatment interruptions of up to 14 days if necessary for the management of certain AEs. Although all reported AEs were captured, it was not possible to identify which AEs led to a treatment interruption for either treatment group. All patients who received a dose reduction from the standard afatinib monotherapy dose of $40 \mathrm{mg} /$ day $(n=63)$ experienced treatment-related AEs prior to dose reduction, $40(63.5 \%)$ of whom experienced grade $\geq 3$ treatment-related AEs (Supplementary Table 1). The most common treatment-related AEs among these patients were diarrhea, rash/ acne, stomatitis and nail effect (grouped terms). Afatinib dose reduction to $<40 \mathrm{mg}$ correlated with a decrease in the incidence of all grade and grade $\geq 3$ treatment-related AEs overall [all grade: $90.5 \%(n=57)$; grade $\geq 3: 23.8 \%(n=15)$ ] and across the key treatment-related AEs including diarrhea, rash/acne and stomatitis (Fig. 1; Supplementary Table 1).

There was no evidence of a significant difference in PFS between patients who had a dose reduction to $<40 \mathrm{mg}$ and those who remained on $\geq 40 \mathrm{mg}$ afatinib for the first 6 months of treatment ( 12.8 vs 11.0 months, HR $=1.34$, 95\% CI 0.90-2.00; $P=0.144$; Fig. 2). In addition, mean EQ-5D and EQ-VAS values at baseline and post-baseline were similar for patients who received $<40 \mathrm{mg} /$ day in the first 6 months of treatment and for patients who received $\geq 40 \mathrm{mg} / \mathrm{day}$ for the first 6 months (baseline to post-baseline mean EQ-5D scores: $<40 \mathrm{mg}, 0.69$ to 0.74 and $\geq 40 \mathrm{mg} 0.73$ to 0.77 ; baseline to post-baseline mean EQ-VAS scores: $<40 \mathrm{mg}, 72.4$ to 70.5 and $\geq 40 \mathrm{mg}, 68.6$ and 75.4; Fig. 3 ).

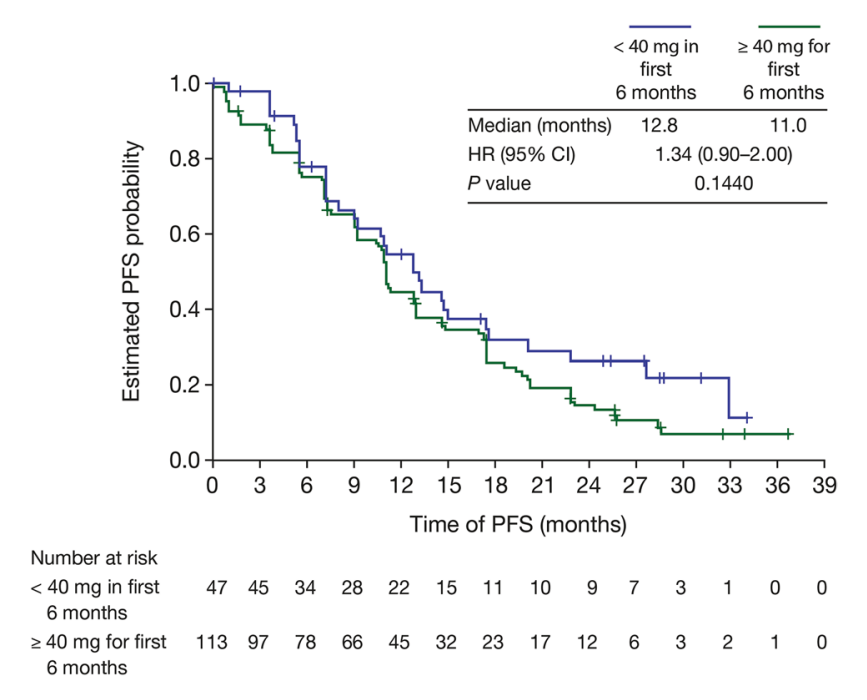

Fig. 2 Median progression-free survival (PFS) in afatinib-treated patients who received a dose reduction to $<40 \mathrm{mg} /$ day and in those who remained on $\geq 40 \mathrm{mg} /$ day in the first 6 months of treatment

\section{Treatment beyond progression}

Baseline demographics and disease characteristics of both afatinib- $(n=56 ; 35.0 \%)$ and gefitinib-treated $(n=47$; $29.6 \%$ ) patients who continued their assigned study treatment beyond initial radiological progression were similar to those of the ITT population (Table 2). As previously reported in the primary PFS/TTF analysis (data cutoff: August 21, 2015), median PFS in the ITT population was 11.0 vs 10.9 months with afatinib vs gefitinib $(\mathrm{HR}=0.73$, 95\% CI 0.57-0.95; $P=0.017)$ and median TTF was 13.7 months vs 11.5 months $(\mathrm{HR}=0.73,95 \%$ CI $0.58-0.92$; $P=0.0073)$ (Park et al. 2016). In a subsequent analysis
Fig. 1 Key treatment-related adverse events (AEs) before and after afatinib dose reduction from $40 \mathrm{mg}(n=63) .{ }^{\mathrm{a}}$ Grouped terms of AEs

\section{Before reduction ( $\geq 40 \mathrm{mg}$ ) After reduction (<40 $\mathrm{mg}$ )}

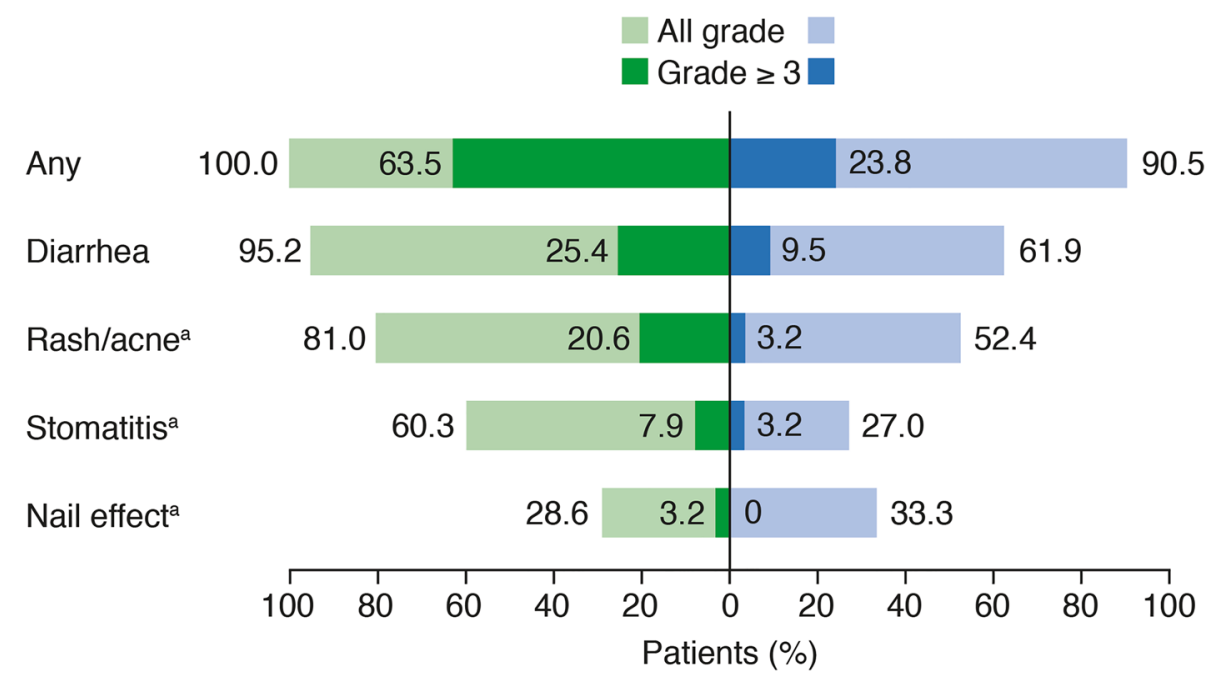


Fig. 3 EuroQol 5 dimensions questionnaire (EQ-5D) and EuroQol Visual Analog Scale (EQ-VAS) scores in afatinib-treated patients who received a dose reduction to $<40 \mathrm{mg}$ /day and in those who remained on $\geq 40 \mathrm{mg} /$ day in the first 6 months of treatment

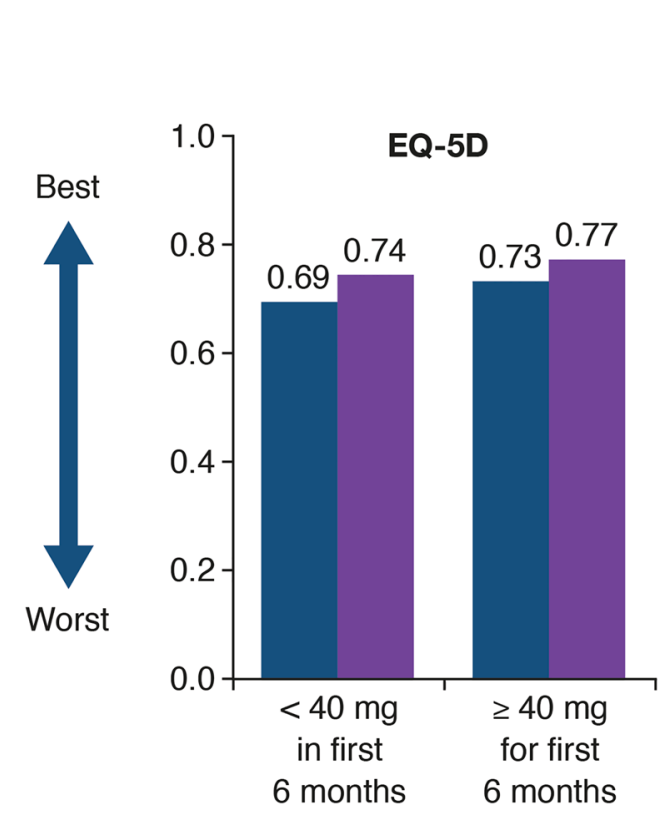

Baseline, mean

Post-baseline, mean (data cutoff: April 08, 2016), similar improvements in PFS and TTF were observed in patients with exon 19 deletion and L858R-positive disease (Supplementary Fig. 1).

A patient could have multiple reasons for radiological progression. Of those patients who continued the assigned treatment beyond initial PD, 24 (42.9\%) afatinib-treated and $26(55.3 \%)$ gefitinib-treated patients had documented PD in target lesions, $29(51.8 \%)$ and $23(48.9 \%)$ patients had a new documented lesion, and $20(35.7 \%)$ and $16(34.0 \%)$ had PD in non-target lesions at the time of initial PD (Supplementary Table 2). Twenty-four (42.9\%) afatinib-treated and nine $(19.1 \%)$ gefitinib-treated patients had a response [partial response (PR)/complete response (CR)] in target lesions at the time of initial PD, but had PD in non-target lesions and/or had new lesions (Supplementary Table 2).

For the 24 afatinib-treated and 26 gefitinib-treated patients who had initial PD in target lesions and continued treatment beyond progression, the median maximum percentage decrease in the sum of target lesion diameters from baseline until the point of initial PD was $44.4 \%$ (range 0-100.0) with afatinib and 51.1\% (range 19.4-100.0) with gefitinib (Supplementary Table 2). Of these, 19 patients (79.2\%) in the afatinib arm and 20 patients $(76.9 \%)$ in the gefitinib arm had an objective response (PR/CR) in target lesions at the time of the nadir (Fig. 4). Median maximum percentage increase in the sum of target lesion diameters from the nadir until the point of initial progression was $42.4 \%$ (range 20.0-220.0) with afatinib and 35.6\% (range 20.4-100.0) with gefitinib. Median time from the nadir to initial PD in target lesions was 6.7 months (range 1.8-30.4) with afatinib and 5.6 months (range 1.8-16.5) with gefitinib (Fig. 4; Supplementary Table 2). There was a pattern toward either a pronounced response in target lesions at the nadir, or a long time to progression and/or a less pronounced increase in the sum of diameters of target lesions from the nadir to initial PD (Fig. 4). At the time of initial PD, two (8.3\%) afatinib-treated patients with PD in target lesions demonstrated CR in non-target lesions, and 15 (62.5\%) afatinibtreated and $18(69.2 \%)$ gefitinib-treated patients with PD in target lesions demonstrated non-CR/non-PD in non-target lesions (Supplementary Table 2).

\section{Discussion}

Effective management of AEs is an important aspect of the overall treatment strategy for patients with advanced NSCLC, with the goal of maximizing therapy exposure, and thus achieving optimal clinical benefit. Consistent with findings from other LUX-Lung studies (Yang et al. 2016), tolerability-guided dose reduction of afatinib in the LUXLung 7 trial led to decreases in the incidence and severity of key treatment-related AEs, particularly diarrhea and rash/ acne.

The majority of afatinib dose reductions occurred within the first 6 months of treatment and were more common in females and non-Asian patients, even taking into account imbalances between gender and race in the ITT populations. In an analysis of afatinib dose reduction in the LUX-Lung 3 and 6 trials, afatinib plasma concentrations, which may vary among distinct subgroups of patients (e.g., based on gender) (Freiwald et al. 2014), were correlated with the incidence of dose reduction (Yang et al. 2016). Mean afatinib trough plasma concentration at the approved starting dose of $40 \mathrm{mg}$ was higher in patients who had subsequent dose reduction, compared with patients who 
Table 2 Baseline demographics and disease characteristics of patients continuing treatment beyond initial PD and the ITT population

\begin{tabular}{|c|c|c|c|}
\hline \multirow[t]{2}{*}{ Characteristic, $n(\%)$} & \multicolumn{3}{|c|}{ Patients continuing treatment beyond initial PD } \\
\hline & Afatinib $(n=56)$ & Gefitinib $(n=47)$ & $\begin{array}{l}\text { ITT population } \\
(n=319) \text { (Park et al. } \\
2016)\end{array}$ \\
\hline \multicolumn{4}{|l|}{ Gender } \\
\hline Male & $27(48.2)$ & $15(31.9)$ & $122(38.2)$ \\
\hline Female & $29(51.8)$ & $32(68.1)$ & $197(61.8)$ \\
\hline Median age, years (range) & $65(39-86)$ & $65(38-86)$ & $63(30-89)$ \\
\hline \multicolumn{4}{|l|}{ Race } \\
\hline Asian & $33(58.9)$ & $22(46.8)$ & $182(57.1)$ \\
\hline Black/African American & $1(1.8)$ & $0(0)$ & $1(0.3)$ \\
\hline White & 19 (33.9) & $18(38.3)$ & $102(32.0)$ \\
\hline Missing $^{\mathrm{a}}$ & $3(5.4)$ & $7(14.9)$ & $34(10.7)$ \\
\hline \multicolumn{4}{|l|}{ Smoking status } \\
\hline Never smoked & 38 (67.9) & $28(59.6)$ & $212(66.5)$ \\
\hline Ex-smoker & $17(30.4)$ & $17(36.2)$ & $98(30.7)$ \\
\hline Currently smokes & $1(1.8)$ & $2(4.3)$ & $9(2.8)$ \\
\hline \multicolumn{4}{|l|}{ Baseline ECOG PS } \\
\hline 0 & $20(35.7)$ & $12(25.5)$ & $98(30.7)$ \\
\hline 1 & $36(64.3)$ & $35(74.5)$ & $221(69.3)$ \\
\hline \multicolumn{4}{|l|}{ Histologic classification } \\
\hline Adenocarcinoma & $56(100.0)$ & $47(100.0)$ & $317(99.4)$ \\
\hline Mixed & $0(0)$ & $0(0)$ & $2(0.6)$ \\
\hline \multicolumn{4}{|l|}{ Clinical stage at screening } \\
\hline IIIB & $0(0)$ & $0(0)$ & $11(3.4)$ \\
\hline IV & $56(100.0)$ & $47(100.0)$ & 308 (96.6) \\
\hline \multicolumn{4}{|l|}{ Metastases at screening } \\
\hline Adrenal glands & $4(7.1)$ & $8(17.0)$ & $28(8.8)$ \\
\hline Bone & $29(51.8)$ & $20(42.6)$ & $153(48.0)$ \\
\hline Brain & $9(16.1)$ & $9(19.1)$ & $50(15.7)$ \\
\hline Liver & $9(16.1)$ & $8(17.0)$ & $40(12.5)$ \\
\hline Lung ipsilateral & $29(51.8)$ & $31(66.0)$ & $174(54.5)$ \\
\hline Lung contralateral & $24(42.9)$ & $23(48.9)$ & $138(43.3)$ \\
\hline Other & $31(55.4)$ & $25(53.2)$ & $204(63.9)$ \\
\hline
\end{tabular}

ECOG PS Eastern Cooperative Oncology Group performance status, ITT intent to treat, $P D$ progressive disease

${ }^{\text {a }}$ Patients recruited in French sites did not have their race recorded did not require dose reduction. Further, afatinib plasma concentrations for those who had dose reduction to $30 \mathrm{mg}$ were similar to those who remained on the $40 \mathrm{mg}$ dose (Yang et al. 2016). Although pharmacokinetic analyses were not conducted in the LUX-Lung 7 trial, the analyses from LUX-Lung 3 and 6, which consisted of a similar patient population and treatment setting, suggest that reducing the dose of afatinib in some patients may serve to mitigate excessive afatinib plasma exposure and thus reduce the burden of common treatment-related AEs. Given that gefitinib is only approved for administration in one dose formulation (European Medicines Agency 2018a; US Food and Drug Administration 2015a), no dose-reduction schemes were implemented for gefitinib in LUX-Lung 7, although dose interruptions were permitted for various reasons. It was not possible to identify AEs that led to a dose interruption due to an oversight in the design of the electronic case record form.

In LUX-Lung 7, there was no evidence of a statistically significant difference in median PFS with afatinib between patients who had a dose reduction to $<40 \mathrm{mg}$ during the first 6 months of treatment vs those who remained on $\geq 40 \mathrm{mg}$ during this time. Due to the inherent confounding in this analysis, as patients with early PD are unlikely to have been given the opportunity to reduce dose, some care should be taken in the interpretation of these results. 
Fig. 4 Percentage change from baseline ${ }^{a}$ in the sum of target lesion (TL) diameters for patients who continued afatinib (a) or gefitinib (b) beyond progressive disease (PD) in TLs. ${ }^{a}$ Until the point of initial disease progression
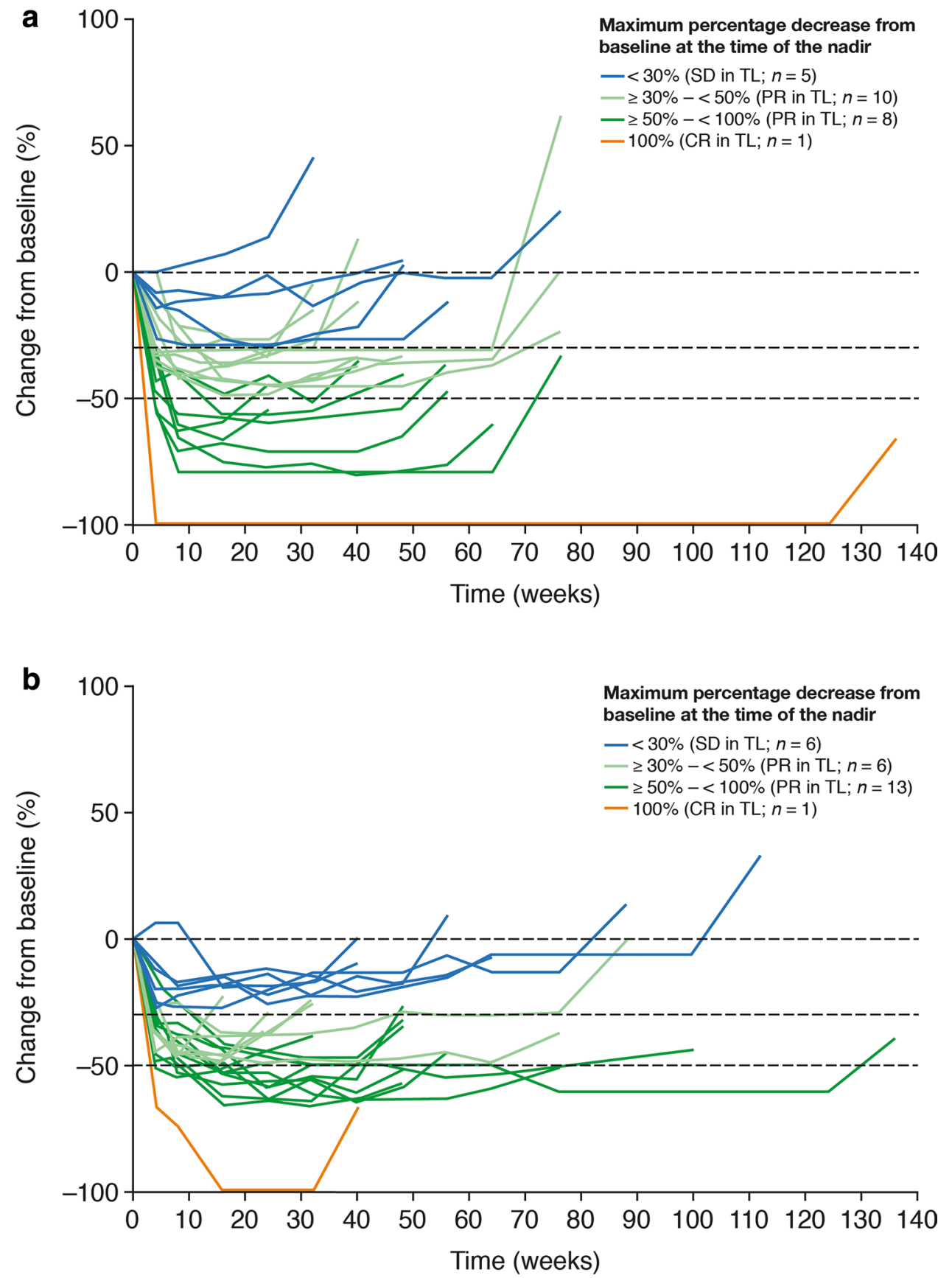

There was no clinically meaningful difference in PROs for patients who received a dose reduction to $<40 \mathrm{mg}$ during the first 6 months of treatment vs those who did not. Combined with the findings from the LUX-Lung 3 and 6 trials (Yang et al. 2016), these data indicate that dose reduction of afatinib is an effective strategy for the management of key treatment-related AEs, without negatively impacting the efficacy in patients with EGFR mutation-positive NSCLC. In the context of these data, it is important to note that there are currently no clinical data to support adaptation of the approved afatinib starting dose based on patient clinical characteristics, and underdosing at initiation of treatment may negatively affect the achievable clinical benefit with afatinib. Thus, the approved afatinib dose of $40 \mathrm{mg} / \mathrm{day}$ is recommended at treatment start and should only be modified based on individual patient tolerability. During the patient's first few months of treatment, there should be frequent, vigilant follow-up and monitoring to ensure timely and appropriate dose adjustments.

Approximately, one-third of patients who were experiencing clinical benefit with afatinib or gefitinib continued their assigned treatments beyond investigator-assessed 
radiological progression (Park et al. 2016). The median duration of the assigned study treatment beyond PD in these patients was 2.7 months with afatinib and 2.0 months with gefitinib, which may suggest some benefit in continuing EGFR TKI treatment beyond radiological progression, with a numerically longer duration of treatment observed in the afatinib vs gefitinib treatment arm (Park et al. 2016). Around half of the patients who continued treatment beyond initial progression had no documented PD in target lesions, but instead had PD in non-target lesions and/or the occurrence of a new lesion, the latter of which might be controlled by localized therapies. At the time of initial progression, $42.9 \%$ of afatinib-treated and $19.1 \%$ of gefitinib-treated patients who continued treatment beyond progression had either a CR or PR in target lesions. Based on these data, from a clinical perspective it seems that progression in nontarget lesions and/or the occurrence of a new lesion, especially in conjunction with responses in target lesions, may not impact a patient's overall clinical disease control in a way that would justify a change of systemic therapy, with an uncertain efficacy of next-line treatment.

Those patients who continued afatinib or gefitinib treatment beyond initial radiological progression in target lesions demonstrated what might be viewed as a 'slow progression'. In general, a gradual increase in the sum of diameters of target lesions over a median of 6-7 months between the time of the nadir and initial PD was observed. Around $70 \%$ of these patients demonstrated responses (CR/PR) or non-CR/ non-PD in non-target lesions, which may suggest that progression in target lesions alone may not be the only factor requiring treatment discontinuation, because patients may still be able to derive clinical benefit from continued EGFR TKI treatment. Patients who continued their assigned treatment beyond progression in target lesions tended to demonstrate either a pronounced response in target lesions at the nadir, or a long time to progression and/or a less pronounced increase in the sum of target lesion diameters from the nadir to initial PD. Investigators deemed it possible for all patients who continued treatment beyond RECIST-defined progression in target lesions to derive further clinical benefit from continued treatment and may define these patients as 'slowprogressors', particularly those with a longer time to progression and/or less pronounced increase in target lesion size from the nadir to initial PD. The characteristics of patients who continued treatment beyond progression were similar in both the afatinib and gefitinib treatment arms, with regard to baseline characteristics and reason for PD (PD in target and/ or non-target lesions, or occurrence of new lesions) (Park et al. 2016).

These findings from the LUX-Lung 7 study provide further support that tolerability-guided dose adjustment of afatinib reduces the incidence and severity of treatmentrelated AEs without affecting the efficacy or diminishing the effects of afatinib on PROs in patients with advanced EGFR mutation-positive NSCLC. Our further findings suggest that treatment beyond progression may allow patients who are deriving clinical benefit, for example, those with 'slow progression' or less clinically relevant new lesions in conjunction with a response in target lesions at the time of initial progression, to maximize time on EGFR TKI treatment. In conclusion, protocol-defined dose adjustment of afatinib may ultimately allow patients to remain on treatment longer, thus maximizing the clinical benefit, even in the presence of radiological disease progression.

Acknowledgements This clinical research was funded by Boehringer Ingelheim Pharmaceuticals Inc. Medical writing assistance, supported financially by Boehringer Ingelheim Pharmaceuticals Inc., was provided by Laura Winton of GeoMed, an Ashfield Company, part of UDG Healthcare plc, during the preparation of this article.

Author contributions Drs. YS, CDA, KK and JL: acquisition of data for this paper; Drs. KOB, E-HT and JC-HY: data analysis or interpretation for this paper; Drs. KHL, SL, D-WK and LZ: acquisition of data and data analysis or interpretation for this paper; Dr. DM: conception or design and data analysis or interpretation for this paper. Drs. MB, VH, S-WK, AM, LP-A, KP and MS: conception or design, acquisition of data and data analysis or interpretation. All authors contributed to the drafting or critical review of the manuscript and provided final approval.

\section{Compliance with ethical standards}

Conflict of interest Dr. O'Byrne has received advisory board fees, speaker bureau fees and travel grants from BMS, MSD, Lilly Oncology, Boehringer Ingelheim, Pfizer, Novartis, Roche-Genentech, Teva and AstraZeneca. Dr. Boyer reports grants from Boehringer Ingelheim, during the conduct of the study, grants from Pfizer, grants and nonfinancial support from Roche and AstraZeneca, outside the submitted work. Dr. Hirsh is a member of the Boehringer Ingelheim advisory board. Dr. Kim D-W reports travel support for advisory meeting from Novartis, outside the submitted work. Dr Märten reports employment from Boehringer Ingelheim, outside the submitted work. Dr. Massey reports employment from Boehringer Ingelheim, outside the submitted work. Dr. Mok reports grants and personal fees from AstraZeneca, Roche/Genentech, BMS, Boehringer Ingelheim, Novartis, MSD, Pfizer, Clovis Oncology, SFJ Pharmaceuticals, Takeda and Taiho, personal fees from Eli Lilly, Merck Serono, Janssen, Vertex, Celgene, ACEA Biosciences, Oncogenex, Ignyta Inc, OrigiMed, Fishawack Facilitate Ltd, Hengrui Therapeutics, Sanofi-Aventis R\&D and Yuhan Corporation, non-financial support from geneDecode, grants from Eisai, personal fees and other from Hutchison ChiMed, grants from XCovery and other from Sanomics, outside the submitted work. Dr. Park reports personal fees from Boehringer Ingelheim for an advisory and consultancy role. Dr. Paz-Ares reports personal fees from Novartis, MSD, BMS, Boehringer Ingelheim, AstraZeneca, Pfizer, Roche, Lilly, Amgen and Clovis, outside the submitted work. Dr. Schuler reports grants and personal fees from Boehringer Ingelheim, during the conduct of the study, grants and personal fees from AstraZeneca, Boehringer Ingelheim, Bristol-Myers Squibb and Novartis and personal fees from Roche, Abbvie, Alexion, Celgene, Lilly, MSD and Pierre Fabre, outside the submitted work. Dr. Yang reports personal fees from Boehringer Ingelheim, Eli Lilly, Roche/Genentech, Chugai, Astellas, MSD, Merck Serono, Pfizer, Novartis, Celgene, Merrimack, Yuhan Pharmaceuticals, BMS, Ono Pharmaceuticals, Daiichi Sankyo, 
AstraZeneca, Hansoh Pharmaceuticals and Takeda Pharmaceuticals, outside the submitted work. Dr. Zhang reports grants from Pfizer, BMS and AstraZeneca, outside the submitted work. The remaining authors declare no conflict of interest.

Data sharing To ensure independent interpretation of clinical study results, Boehringer Ingelheim grants all external authors access to all relevant material, including participant-level clinical study data and relevant material as needed by them to fulfill their role and obligations as authors under the ICMJE criteria. Furthermore, clinical study documents (e.g., study report, study protocol, statistical analysis plan) and participant clinical study data are available to be shared after publication of the primary manuscript in a peer-reviewed journal and if regulatory activities are complete and other criteria met per the BI Policy on Transparency and Publication of Clinical Study Data: https://trials.boehringer-ingelheim.com/transparency_policy.html. Prior to providing access, documents will be examined, and, if necessary, redacted and the data will be de-identified, to protect the personal data of study participants and personnel, and to respect the boundaries of the informed consent of the study participants. Clinical Study Reports and Related Clinical Documents can be requested via this link: https://trials.boehringer-ingelheim.com/trial_results/clinical_submi ssion_documents.html. All such requests will be governed by a Document Sharing Agreement. Bona fide, qualified scientific and medical researchers may request access to de-identified, analyzable participant clinical study data with corresponding documentation describing the structure and content of the datasets. Upon approval, and governed by a Data Sharing Agreement, data are shared in a secured data-access system for a limited period of 1 year, which may be extended upon request. Researchers should use https://clinicalstudydatarequest.com to request access to study data.

OpenAccess This article is distributed under the terms of the Creative Commons Attribution 4.0 International License (http://creativeco mmons.org/licenses/by/4.0/), which permits unrestricted use, distribution, and reproduction in any medium, provided you give appropriate credit to the original author(s) and the source, provide a link to the Creative Commons license, and indicate if changes were made.

\section{References}

Chaft JE, Oxnard GR, Sima CS, Kris MG, Miller VA, Riely GJ (2011) Disease flare after tyrosine kinase inhibitor discontinuation in patients with EGFR-mutant lung cancer and acquired resistance to erlotinib or gefitinib: implications for clinical trial design. Clin Cancer Res 17:6298-6303

Corral J, Park K, Yang JC-H, Mok T, Tan E-H, O'Byrne K, Hirsh V, Boyer M, Fan J, Zhang L (2017) Afatinib versus gefitinib in patients with EGFR mutation-positive (EGFRm+) NSCLC: Updated overall survival data from the phase IIb trial LUX-Lung 7. Ann Oncol 28(suppl 2):ii28-ii51

Eisenhauer EA, Therasse P, Bogaerts J, Schwartz LH, Sargent D, Ford R, Dancey J, Arbuck S, Gwyther S, Mooney M, Rubinstein L, Shankar L, Dodd L, Kaplan R, Lacombe D, Verweij J (2009) New response evaluation criteria in solid tumours: revised RECIST guideline (version 1.1). Eur J Cancer 45:228-247

European Medicines Agency (2018a) Iressa ${ }^{\circledR}$ (gefitinib) summary of product characteristics. http://www.ema.europa.eu/docs/en_GB/ document_library/EPAR_-_Product_Information/human/00101 6/WC500036358.pdf. Accessed 15 Oct 2018

European Medicines Agency (2018b) Tarceva ${ }^{\circledR}$ (erlotinib) summary of product characteristics. http://www.ema.europa.eu/docs/en_GB/
document_library/EPAR_-_Product_Information/human/00061 8/WC500033994.pdf. Accessed 15 Oct 2018

European Medicines Agency (2018c) Giotrif ${ }^{\circledR}$ (afatinib) summary of product characteristics. http://www.ema.europa.eu/docs/en_GB/ document_library/EPAR_-_Product_Information/human/00228 0/WC500152392.pdf. Accessed 15 Oct 2018

European Medicines Agency (2018d) Tagrisso ${ }^{\circledR}$ (osimertinib) summary of product characteristics. http://www.ema.europa.eu/docs/ en_GB/document_library/EPAR_-_Product_Information/human /004124/WC500202022.pdf. Accessed 15 Oct 2018

Freiwald M, Schmid U, Fleury A, Wind S, Stopfer P, Staab A (2014) Population pharmacokinetics of afatinib, an irreversible ErbB family blocker, in patients with various solid tumors. Cancer Chemother Pharmacol 73:759-770

National Cancer Institute (2006) Common terminology criteria for adverse events, version 3.0. https://ctep.cancer.gov/protocolDe velopment/electronic_applications/docs/ctcaev3.pdf. Accessed 15 Oct 2018

Novello S, Barlesi F, Califano R, Cufer T, Ekman S, Levra MG, Kerr K, Popat S, Reck M, Senan S, Simo GV, Vansteenkiste J, Peters S, ESMO Guidelines Committee (2016) Metastatic non-small-cell lung cancer: ESMO Clinical Practice Guidelines for diagnosis, treatment and follow-up. Ann Oncol 27(suppl 5):v1-v27

Park K, Tan EH, O’Byrne K, Zhang L, Boyer M, Mok T, Hirsh V, Yang JC, Lee KH, Lu S, Shi Y, Kim SW, Laskin J, Kim DW, Arvis CD, Kolbeck K, Laurie SA, Tsai CM, Shahidi M, Kim M, Massey D, Zazulina V, Paz-Ares L (2016) Afatinib versus gefitinib as first-line treatment of patients with EGFR mutation-positive non-small-cell lung cancer (LUX-Lung 7): a phase 2B, open-label, randomised controlled trial. Lancet Oncol 17:577-589

Paz-Ares L, Tan EH, O’Byrne K, Zhang L, Hirsh V, Boyer M, Yang JC, Mok T, Lee KH, Lu S, Shi Y, Lee DH, Laskin J, Kim DW, Laurie SA, Kolbeck K, Fan J, Dodd N, Marten A, Park K (2017) Afatinib versus gefitinib in patients with EGFR mutation-positive advanced non-small-cell lung cancer: overall survival data from the phase IIb LUX-Lung 7 trial. Ann Oncol 28:270-277

Riely GJ, Kris MG, Zhao B, Akhurst T, Milton DT, Moore E, Tyson L, Pao W, Rizvi NA, Schwartz LH, Miller VA (2007) Prospective assessment of discontinuation and reinitiation of erlotinib or gefitinib in patients with acquired resistance to erlotinib or gefitinib followed by the addition of everolimus. Clin Cancer Res 13:5150-5155

Sequist LV, Yang JC, Yamamoto N, O’Byrne K, Hirsh V, Mok T, Geater SL, Orlov S, Tsai CM, Boyer M, Su WC, Bennouna J, Kato T, Gorbunova V, Lee KH, Shah R, Massey D, Zazulina V, Shahidi M, Schuler M (2013) Phase III study of afatinib or cisplatin plus pemetrexed in patients with metastatic lung adenocarcinoma with EGFR mutations. J Clin Oncol 31:3327-3334

US Food and Drug Administration (2010) Tarceva ${ }^{\circledR}$ (erlotinib) highlights of prescribing information. https://www.accessdata.fda.gov/ drugsatfda_docs/label/2010/021743s14s16lbl.pdf. Accessed 15 Oct 2018

US Food and Drug Administration (2013) Gilotrif ${ }^{\circledR}$ (afatinib) highlights of prescribing information. https://www.accessdata.fda. gov/drugsatfda_docs/label/2013/201292s0001bl.pdf. Accessed 15 Oct 2018

US Food and Drug Administration (2015a) Iressa ${ }^{\circledR}$ (gefitinib) highlights of prescribing information. https://www.accessdata.fda. gov/drugsatfda_docs/label/2015/206995s000lbl.pdf. Accessed 15 Oct 2018

US Food and Drug Administration (2015b) Tagrisso ${ }^{\circledR}$ (osimertinib) highlights of prescribing information. https://www.accessdata.fda. gov/drugsatfda_docs/label/2015/208065s000lbl.pdf. Accessed 15 Oct 2018

US Food and Drug Administration (2018) Vizimpro ${ }^{\circledR}$ (dacomitinib) highlights of prescribing information. https://www.accessdata.fda. 
gov/drugsatfda_docs/label/2018/211288s000lbl.pdf. Accessed 15 Oct 2018

Wu YL, Zhou C, Hu CP, Feng J, Lu S, Huang Y, Li W, Hou M, Shi JH, Lee KY, Xu CR, Massey D, Kim M, Shi Y, Geater SL (2014) Afatinib versus cisplatin plus gemcitabine for first-line treatment of Asian patients with advanced non-small-cell lung cancer harbouring EGFR mutations (LUX-Lung 6): an open-label, randomised phase 3 trial. Lancet Oncol 15:213-222

Wu YL, Cheng Y, Zhou X, Lee KH, Nakagawa K, Niho S, Tsuji F, Linke R, Rosell R, Corral J, Migliorino MR, Pluzanski A, Sbar EI, Wang T, White JL, Nadanaciva S, Sandin R, Mok TS (2017) Dacomitinib versus gefitinib as first-line treatment for patients with EGFR-mutation-positive non-small-cell lung cancer (ARCHER 1050): a randomised, open-label, phase 3 trial. Lancet Oncol 18:1454-1466

Yang JC, Sequist LV, Zhou C, Schuler M, Geater SL, Mok T, Hu CP, Yamamoto N, Feng J, O’Byrne K, Lu S, Hirsh V, Huang Y,
Sebastian M, Okamoto I, Dickgreber N, Shah R, Marten A, Massey D, Wind S, Wu YL (2016) Effect of dose adjustment on the safety and efficacy of afatinib for EGFR mutation-positive lung adenocarcinoma: post hoc analyses of the randomized LUX-Lung 3 and 6 trials. Ann Oncol 27:2103-2110

Yap TA, Macklin-Doherty A, Popat S (2017) Continuing EGFR inhibition beyond progression in advanced non-small cell lung cancer. Eur J Cancer 70:12-21

Publisher's Note Springer Nature remains neutral with regard to jurisdictional claims in published maps and institutional affiliations.

\section{Affiliations}

\section{Martin Schuler ${ }^{1}$ (1) Eng-Huat Tan ${ }^{2} \cdot$ Kenneth O'Byrne $^{3} \cdot$ Li Zhang $^{4} \cdot$ Michael Boyer $^{5} \cdot$ Tony Mok $^{6} \cdot$ Vera Hirsh $^{7}$. James Chih-Hsin Yang ${ }^{8} \cdot \mathrm{Ki} \mathrm{Hyeong} \mathrm{Lee}^{9} \cdot$ Shun Lu $^{10} \cdot$ Yuankai Shi $^{11}$. Sang-We Kim ${ }^{12}$. Janessa Laskin ${ }^{13}$. Dong-Wan Kim ${ }^{14} \cdot$ Catherine Dubos Arvis $^{15} \cdot$ Karl Kölbeck $^{16}$. Dan Massey ${ }^{17}$. Angela Märten ${ }^{18} \cdot$ Luis Paz-Ares $^{19}$. Keunchil Park ${ }^{20}$}

1 West German Cancer Center, University Hospital Essen, University Duisburg-Essen, Hufelandstrasse 55, 45147 Essen, Germany

2 Department of Medical Oncology, National Cancer Centre, 11 Hospital Drive, Singapore, Singapore

3 Cancer Services, Princess Alexandra Hospital and Queensland University of Technology, 199 Ipswich Rd, Woolloongabba, Brisbane 4102, Australia

4 Department of Medical Oncology, Cancer Center of Sun Yat-Sen University, 651 Dong Feng Road, Guangzhou 510060, China

5 Department of Oncology, Chris O’Brien Lifehouse, 119-143 Missenden Road, Camperdown, NSW 2050, Australia

6 Department of Clinical Oncology, The Chinese University of Hong Kong, Chung Chi Road, Hong Kong, China

7 Department of Oncology, McGill University Health Centre, 1001 Décatie Blvd, Montreal, QC H4A 3JI, Canada

8 Department of Oncology, National Taiwan University Hospital and National Taiwan University Cancer Center, 7 Chung-Shan South Road, Taipei 100, Taiwan

9 Department of Internal Medicine, Chungbuk National University Hospital, Chungcheongbuk-do, Cheongju, South Korea

10 Department of Lung Cancer, Shanghai Chest Hospital, Shanghai, China
11 National Cancer Center/National Clinical Research Center for Cancer/Cancer Hospital, Chinese Academy of Medical Sciences and Peking Union Medical College, No. 17, Panjiayuan Nanli, Chaoyang District, Beijing 100021, China

12 Asan Medical Center, University of Ulsan College of Medicine, 93 Daehak-ro, Seoul, South Korea

13 Department of Medical Oncology, BC Cancer Agency, 600 W 10th Avenue, Vancouver, BC V5Z 4E6, Canada

14 Department of Internal Medicine, Seoul National University Hospital, 101 Daehak-ro, Jongno-gu, Seoul, South Korea

15 Department of Oncology, Centre François Baclesse, 3 Avenue du Général Harris, 14000 Caen, France

16 Department of Respiratory Medicine and Allergology, Karolinska University Hospital, 17176 Stockholm, Sweden

17 Statistics, Boehringer Ingelheim Ltd, Ellesfield Avenue, Bracknell RG12 8YS, UK

18 Global Medicine, Boehringer Ingelheim International GmbH, Binger Straße 173, 55216 Ingelheim am Rhein, Germany

19 Department of Medical Oncology, Hospital Universitario Doce de Octubre, CiberOnc, Universidad Complutense and CNIO, Av. Cordoba, s/n, 28041 Madrid, Spain

20 Department of Medicine, Samsung Medical Center, Sungkyunkwan University School of Medicine, 50 Irwondong, Gangnam-gu, Seoul 135-710, South Korea 